\title{
PENILAIAN KEBERLANJUTAN PENGELOLAAN SISTEM PENYEDIAAN AIR MINUM BERBASIS MASYARAKAT DI KOTA BLITAR
}

\author{
Puji Kamulyan ${ }^{a}$, I Putu Artama Wiguna ${ }^{b}$ dan Agus Slamet ${ }^{c}$
}

\begin{abstract}
The paper disccuses an assess the sustainability level, to identify important and priority factors of Community Based Water Supply System (CBWSS) management. Public and stakeholders perception are the main data needed for the analysis, and these data are collected through observation and structured interviews. The consideration aspects to measure the sustainability level consist of technical,institutional, financial, social and environmental aspects. This study used several analysis methods, i.e. Index Formulation (measuring sustainability level), Relative Importance Index and Confidence Interval (identifying important factors) and Development Priority Index (determining priority factors). The results indicate that CBWSS management is generally quite sustainable, with the highest sustainability value on environmental aspect, while the lowest one is on social aspect. The most important factor in the CBWSS management is the existence of community retribution and the development priority factor lead to the management transparency.
\end{abstract}

Keywords: sustainability assessment, management, Relative Impotance Index, CBWSS, Blitar

Abstrak: Makalah ini menyajikan hasil studi penilaian tingkat keberlanjutan pengelolaan, identifikasi faktor penting dan faktor prioritas pengembangan pada Sistem Penyediaan Air Minum berbasis masyarakat.Persepsi masyarakat dan pemangku kepentingan merupakan data utama yang dikumpulkan melalui observasi dan wawancara terstruktur. Aspek keberlanjutan yang dinilai meliputi aspek teknis, kelembagaan, keuangan, sosial dan lingkungan. Penelitian ini menggunakan beberapa metode analisa, antara lain:Rumus Indeks untuk menilai tingkat keberlanjutan, uji Relative Importance Index (RII) dan Confidence Interval (CI) untuk identifikasi faktor penting, sedangkan untuk menyusun faktor prioritas menggunakan Indeks Prioritas Pengembangan (IPP). Hasil penelitian menunjukkan secara umum pengelolaan SPAM berbasis masyarakat di Kota Blitar cukup berkelanjutan dengan aspek lingkungan memiliki nilai keberlanjutan tertinggi, sedangkan aspek dengan nilai kebelanjutan terendah adalah aspek sosial. Adapun faktor paling penting dalam pengelolaan SPAM adalah keberadaan iuran masyarakat sedangkan faktor yang merupakan prioritas pengembangan adalah faktor transparansi pengelolaan.

Kata Kunci: penilaian keberlanjutan,pengelolaan, SPAM berbasis masyarakat,Relative Importance Index, Blitar

\section{PENDAHULUAN}

Penyelenggaraan Sistem Penyediaan Air Minum (SPAM) berbasis masyarakat kota Blitar ditujukan untuk masyarakat berpenghasilan rendah yang belum terlayani penyediaan air minum secara formal oleh Perusahaan Daerah Air Minum. Untuk menjaga agar SPAM berkelanjutan maka perlu dibentuk lembaga di tingkat masyarakat sebagai penyelenggara SPAM. Lembaga SPAM dapat menciptakan mekanisme pengelolaan dan pemeliharaan. Penyelenggaraan pengelolaan prasarana air minum terbangun dilaksanakan oleh PDAM, BLU, UPTD, Organisasi Masyarakat Setempat-Air Minum (OMS-AM), Koperasi Air Minum, dan Kelompok Pengguna dan Pemanfaat. Bila masyarakat tidak mampu melaksanakan pemeliharaan, pemerintah daerah berkewajiban memberikan pelatihan yang berkaitan dengan pengelolaan kepada masyarakat [1].

Schuringa [2] mendefinisikan sistem penyediaan air dikatakan berkelanjutan ketika : sistem itu berfungsi dan

${ }^{a}$ Personnel at Dinas Pekerjaan Umum dan Penataan Ruang Kota Blitar and a Student in the Department of Civil Engineering, Sepuluh Nopember Institute of Technology (ITS), ITS Campus, Sukolilo, Surabaya 60111, Indonesia. Email: puji_kamulyan@yahoo.com

${ }^{b}$ Lecturer in the Department of Civil Engineering, Sepuluh Nopember Institute of Technology (ITS), ITS Campus, Sukolilo, Surabaya 60111, Indonesia. Email: artama@ce.its.ac.id

'Lecturer in the Department of Environmental Engineering, Sepuluh Nopember Institute of Technology (ITS), ITS Campus, Sukolilo, Surabaya 60111, Indonesia. Email: agus_tlits@gmail.com

Note. The manuscript for this paper was submitted for review and possible publication on August 08, 2017. This paper is part of the ITS Journal of Civil Engineering, Vol. 32, No. 2, November 2017. (C) ITS Journal of Civil Engineering, ISSN 2579-9029/2017. digunakan, sistem tersebut mampu memberikan tingkat manfaat yang sesuai (kualitas, kuantitas, keteraturan, kesediaan, efisiensi, kesetaraan, keandalan dan kesehatan), berjalan dalam jangka waktu yang lama tanpa berdampak buruk pada lingkungan, semua pembiayaan operasional dan pemeliharaan terpenuhi, terdapat lembaga yang mengelola, dan mendapat dukungan yang layak dari pihak luar. Sedangkan faktor-faktor yang mempengaruhi keberlanjutan adalah faktor sosial, faktor teknis, faktor lingkungan, faktor keuangan dan faktor kelembagaan. berkelanjutan.

Jones dkk [3] dalam penelitiannya tentang pendekatan siklus hidup untuk meningkatkan keberlanjutan sistem penyediaan air perdesaan pada negara dengan keterbatasan sumber air, memperoleh hasil bahwa faktorfaktor yang berpengaruh terhadap keberlanjutan adalah: faktor teknis, lingkungan, kelembagaan, komunitas dan manajerial, finansial dan faktor kesehatan manusia.

Penelitian yang dilakukan oleh Aslam [4] tentang keberlanjutan sistem air minum berbasis masyarakat di negera berkembang menggolongkan komponenkomponen evaluasi keberlanjutan sebagai berikut komponen teknis (desain, perawatan dan kualitas air pada sistem distribusi), lingkungan (kapasitas dan kualitas sumber air), sosial (kesadaran dan keterlibatan sosial), ekonomi (pembiayaan dan dampak ekonomi), dan institusi (organisasi masyarakat dan unit operasional pemeliharaan).

Penyediaan air minum melalui SPAM berbasis masyarakat merupakan program Dana Alokasi Khusus Air Minum (DAK AM) dan dilaksanakan di tiga belas lokasi. Prasarana yang dibangun meliputi: unit air baku, unit produksi, unit distribusi dan unit pelayanan. Analisa 
dokumen Rencana Induk SPAM Kota Blitar menunjukkan bahwa prasarana yang telah terbangun mengalami permasalahan, diantaranya tidak berjalannya operasional pemeliharaan, adanya kerusakan teknis, menurunnya jumlah pengguna dan rendahnya partisipasi masyarakat . Oleh karena itu, perlu dilakukan kajian mengenai keberlanjutan pengelolaan SPAM ditinjau dari aspek teknis, kelembagaan, ekonomi, sosial dan lingkungan.

Melalui penelitian ini dapat diketahui bagaimana tingkat keberlanjutan pengelolaan, identifikasi faktor penting dan faktor prioritas pengembangan pada SPAM berbasis masyarakat di kota Blitar. Penelitian ini diharapkan dapat menjadi bahan kajian penerapan evaluasi pembangunan dan pengelolaan prasarana penyediaan air minum berbasis masyarakat di kota Blitar.

\section{METODOLOGI}

Variabel penilaian keberlanjutan pengelolaan SPAM merupakan sistesis dari peraturan perundangan dan penelitian tentang keberlanjutan penyediaan air minum terdahulu. Dengan pembahasan antara lain memuat aspek dan faktor penelitian pada Tabel 2 berikut.

\section{Penilaian Tingkat Keberlanjutan}

Analisa tingkat keberlanjutan berasal dari persepsi responden terhadap kondisi keberlanjutan pengelolaan
SPAM saat ini. Skala pengukuran yang digunakan untuk mengukur sikap, pendalpat dan persepsi seseorang atau sekelompok orang tentang fenomena sosial adalah skala likert [5]. Dalam penelitian ini scoring jawaban menggunakan rating scale $1 \mathrm{~s} / \mathrm{d} 5$.

Hasil penilaian tersebut kemudian dihitung untuk mengetahui tingkat keberlanjutan dengan menggunakan rumus indeks sebagai berikut.

Rumus Indeks $=$ Total Skor Faktor Penilaian

\section{Total Skor Maksimal}

Setelah masing-masing faktor terhitung nilai indeks keberlanjutannya maka akan dijumlahkan untuk kemudian dibagi rata-rata hasil masing-masing aspek. Hasil pembagian tersebut akan dibandingkan dengan tingkat status keberlanjutan pengelolaan SPAM sebagaimana Tabel 1 berikut:

Tabel 1. Status Kategori Keberlanjutan

\begin{tabular}{ll}
\hline Nilai Indeks & Kategori \\
\hline $0,00-19,99$ & Tidak Berkelanjutan \\
\hline $20,00-39,99$ & Kurang Berkelanjutan \\
\hline $40,00-59,99$ & Cukup Berkelanjutan \\
\hline $60,00-79,99$ & Berkelanjutan \\
\hline $80,00-100$ & Sangat Berkelanjutan \\
\hline
\end{tabular}

Tabel 2. Aspek dan Faktor Penilaian Keberlanjutan Pengelolaan SPAM

\begin{tabular}{|c|c|c|c|c|}
\hline No & Aspek & Faktor & Kode & Sub Faktor \\
\hline \multirow[t]{11}{*}{1} & \multirow[t]{11}{*}{ Teknis } & \multirow{2}{*}{ Unit Air Baku } & I.1 & Kualitas Air Baku \\
\hline & & & I. 2 & Ketersediaan Air Baku \\
\hline & & \multirow[t]{2}{*}{ Unit Produksi } & I. 3 & Kinerja Pompa \\
\hline & & & I.4 & Ketersediaan Suku Cadang \\
\hline & & \multirow[t]{2}{*}{ Unit Distribusi } & $\mathrm{I} .5$ & Kinerja Reservoir \\
\hline & & & I.6 & Kinerja Pipa Distribusi \\
\hline & & \multirow[t]{2}{*}{ Unit Sambungan Rumah } & I.7 & Penambahan Sambungan Rumah \\
\hline & & & I.8 & Cakupan Pelayanan \\
\hline & & \multirow{3}{*}{ Pemenuhan unsur $3 \mathrm{~K}$} & I.9 & Kualitas Air yang diterima \\
\hline & & & I.10 & Kuantitas Air yang diterima \\
\hline & & & I.11 & Kontinuitas Air yang diterima \\
\hline \multirow[t]{6}{*}{2} & \multirow[t]{6}{*}{ Kelembagaan } & \multirow[t]{2}{*}{ Kepengelolaan } & II.1 & Keberadaan Pengelola \\
\hline & & & II. 2 & Kinerja Pengelola \\
\hline & & \multirow[t]{2}{*}{ Tata Tertib Pengelolaan } & II.3 & Transparansi Pengelolaan \\
\hline & & & II.4 & Keberadaan Peraturan \\
\hline & & \multirow[t]{2}{*}{ Kepuasan Pengguna } & II.5 & Kepuasan Pengguna \\
\hline & & & II.6 & Tanggap Pengaduan Pengguna \\
\hline \multirow[t]{5}{*}{3} & \multirow[t]{5}{*}{ Keuangan } & \multirow[t]{3}{*}{ Iuran } & III.1 & Keberadaan Iuran Masyarakat \\
\hline & & & III. 2 & Keterjangkauan Iuran \\
\hline & & & III.3 & Keteraturan Pembayaran Iuran \\
\hline & & \multirow{2}{*}{$\begin{array}{l}\text { Biaya Operasional } \\
\text { Pemeliharaan (BOP) }\end{array}$} & III.4 & Kesesuaian Iuran dengan Biaya Operasional Pemeliharaan \\
\hline & & & III.5 & Keberadaan Biaya Pengembangan \\
\hline \multirow[t]{5}{*}{4} & \multirow[t]{5}{*}{ Sosial } & \multirow[t]{2}{*}{ Keterlibatan Sosial } & IV.1 & Partisipasi Masyarakat \\
\hline & & & IV.2 & Pertemuan Masyarakat \\
\hline & & \multirow[t]{3}{*}{ Kesadaran Sosial } & IV.3 & Kepedulian \\
\hline & & & IV.4 & Keinginan Berkelanjutan \\
\hline & & & IV.5 & Praktek penggunaan air \\
\hline 5 & Lingkungan & Perlindungan Lingkungan & V.1 & Perlindungan Sumber Air \\
\hline
\end{tabular}


Pembahasan hasil penelitian menggunakan analisis statistik deskriptif. Sedangkan jenis sampling yang dipilih adalah stratified random sampling. Responden adalah pengelola dan pengguna SPAM berbasis masyarakat yang terdistribusi secara proporsional pada masing-masing unit lokasi SPAM seperti ditujukkan pada Tabel 3 berikut.

Tabel 3. Responden Penilaian Keberlanjutan

\begin{tabular}{llcc}
\hline No & \multicolumn{1}{c}{ Unit SPAM } & SR Aktif & Sampel \\
\hline 1 & SPAM Ar Rohmah & 40 & 9 \\
\hline 2 & SPAM Walisongo & 3 & 2 \\
\hline 3 & SPAM Tarbiyatul Fallah & 2 & 2 \\
\hline 4 & SPAM Al Ikhsan & 1 & 2 \\
\hline 5 & SPAM Ngrebo & 26 & 6 \\
\hline 6 & SPAM Ngegong & 18 & 4 \\
\hline 7 & SPAM Aren & 97 & 21 \\
\hline 8 & SPAM Wakhid Hasyim & 50 & 12 \\
\hline 9 & SPAM Pakubuwono & 63 & 11 \\
\hline 10 & SPAM Ciliwung & 0 & 1 \\
\hline 11 & SPAM Bendo & 0 & 2 \\
\hline 12 & SPAM Ngadirejo 1 & 3 & 2 \\
\hline 13 & SPAM Ngadirejo 2 & 0 & 78 \\
\hline Responden Pengguna SPAM & & 18 \\
\hline Responden Pengelola SPAM & & \\
\hline
\end{tabular}

\section{Penilaian Faktor Penting}

Untuk menilai faktor yang paling penting dalam pengelolaan SPAM berbasis masyarakat dapat menggunakan uji Relatif Importance Index (RII) sebagai berikut :

$R I I=\frac{\sum P i U i}{N(n)}$

Dengan;

$$
\begin{aligned}
\mathrm{RII} & =\text { Relative importance index } \\
\mathrm{N} & =\text { Jumlah responden } \\
\mathrm{n} & =\text { Angka tertinggi } \\
\mathrm{Pi} & =\begin{array}{l}
\text { Skala likert dimana Ii skala paling rendah } \\
\text { dan In skala paling tinggi }
\end{array} \\
\mathrm{Ui}= & \begin{array}{l}
\text { Frekuensi nilai skala yang dipilih responden } \\
\text { dari } \mathrm{i}=1 \text { sampai dengan } \mathrm{n}
\end{array}
\end{aligned}
$$

Selain menggunakan uji RII untuk mendapatkan urutan faktor yang berpengaruh terhadap keberlanjutan pengelolaan, uji Confidence Interval dapat dilakukan untuk mendukung data penelitian dan memperkuat hasil peringkat yang diperoleh dari uji RII. Confidence Interval adalah sebuah interval yang berdasarkan observasi sampel dan terdaftar probabilitas yang ditentukan [6]. Adapun perhitungan Batas Atas (BA) dan Batas Bawah (BB) adalah sebagai berikut:

$\mathrm{BA}=(\mathrm{X}+1,96 \times(\mathrm{ST} / \sqrt{ } \mathbf{N}))$

$\mathrm{BB}=(\mathrm{X}-1,96 \times(\mathbf{S T} / \sqrt{ } \mathbf{N}))$

Dengan;
$\mathrm{BA}=$ Batas atas (nilai terhadap adanya keterkaitan pada batas atas)
$\mathrm{BB}=$ Batas bawah (nilai terhadap adanya keterkaitan batas bawah)
$\mathrm{X}=$ Rata-rata dari total variabel
ST $=$ Standard deviasi
$\mathrm{N}=$ Jumlah responden

Responden pada analisa penilaian faktor penting adalah stakeholder yang terlibat dalam pengelolaan dan pengambilan kebijakan SPAM berbasis masyarakat di Kota Blitar. Adapun responden tersebut adalah sebagaimana terdapat pada Tabel 4 berikut.

Tabel 4. Responden Penilaian Faktor Penting

\begin{tabular}{cll}
\hline No & \multicolumn{1}{c}{ Responden } & \multicolumn{1}{c}{ Jumlah } \\
\hline 1 & Dinas PU dan Penataan Ruang & 4 orang \\
\hline 2 & Pengelola SPAM & 6 orang \\
\hline & Total & 10 orang \\
\hline
\end{tabular}

\section{Penyusunan Prioritas Pengembangan}

Analisa prioritas pengembangan merupakan metode penyusunan prioritas penanganan faktor yang perlu dikembangkan agar faktor tersebut meningkat keberlanjutannya. Analisa ini menggunakan data hasil analisa penilaian keberlanjutan dan faktor penting dalam keberlanjutan pengelolaan SPAM. Adapun metode analisa merupakan adopsi dari metode analisa Wijayanto [7]. Tahapan yang dilakukan dalam melakukan analisa adalah sebagai berikut:

1. Menentukan key factors, yaitu merupakan faktor keberlanjutan pengelolaan yang digunakan dalam penelitian. Nilai key factors yang digunakan adalah hasil rata-rata pada analisa nilai keberlanjutan sekarang (NKS) dan nilai faktor penting (NP).

2. Data mengenai nilai keberlanjutan sekarang (NKS) diperoleh dari hasil rata-rata penilaian tingkat keberlanjutan, sedangkan nilai penting (NP) merupakan hasil rata-rata penilaian faktor penting dalam keberlanjutan pengelolaan SPAM.

3. Memetakan key factors ke dalam 4 kuadran sesuai hasil penilaian. Kuadran I (NKS $<3, \mathrm{NP}>3$ ) merupakan prioritas pengembangan. Kuadran II $(\mathrm{NKS}>3, \mathrm{NP}>3)$ merupakan prioritas dipertahankan. Kuadran III (NKS>3, NP<3) merupakan faktor dipertahankan tetapi bukan prioritas. Kuadran IV $(\mathrm{NKS}<3, \mathrm{NP}<3)$ merupakan kelompok faktor perlu diperbaiki, tetapi bukan prioritas.

4. Menyusun prioritas permasalahan per kuadran yang harus dicarikan solusi dengan rumus sebagai berikut:

NKSS $=\frac{1}{\mathrm{NKS}} \times(-5)$

IPP $=$ NKSS X NP

Dengan;

$\begin{aligned} & \text { NKSS }= \text { Nilai konversi kondisi sekarang } \\ &(-5 \mathrm{~s} / \mathrm{d}-1) \\ & \text { NKS }=\begin{array}{l}\text { Nilai kondisi sekarang/ nilai keberlanjutan } \\ \text { sekarang }(1 \mathrm{~s} / \mathrm{d} 5)\end{array} \\ & \mathrm{IPP}=\begin{array}{l}\text { Indeks prioritas pengembangan } \\ (-25 \mathrm{~s} / \mathrm{d}-1)\end{array} \\ & \mathrm{NP} \quad=\text { Nilai penting }\end{aligned}$

5. Semakin kecil nilai IPP per kuadran, maka key factors tersebut menjadi semakin diprioritaskan untuk diperbaiki. Adapun kuadran nilai penting dan nilai keberlanjutan sekarang terdapat pada Gambar 1. 


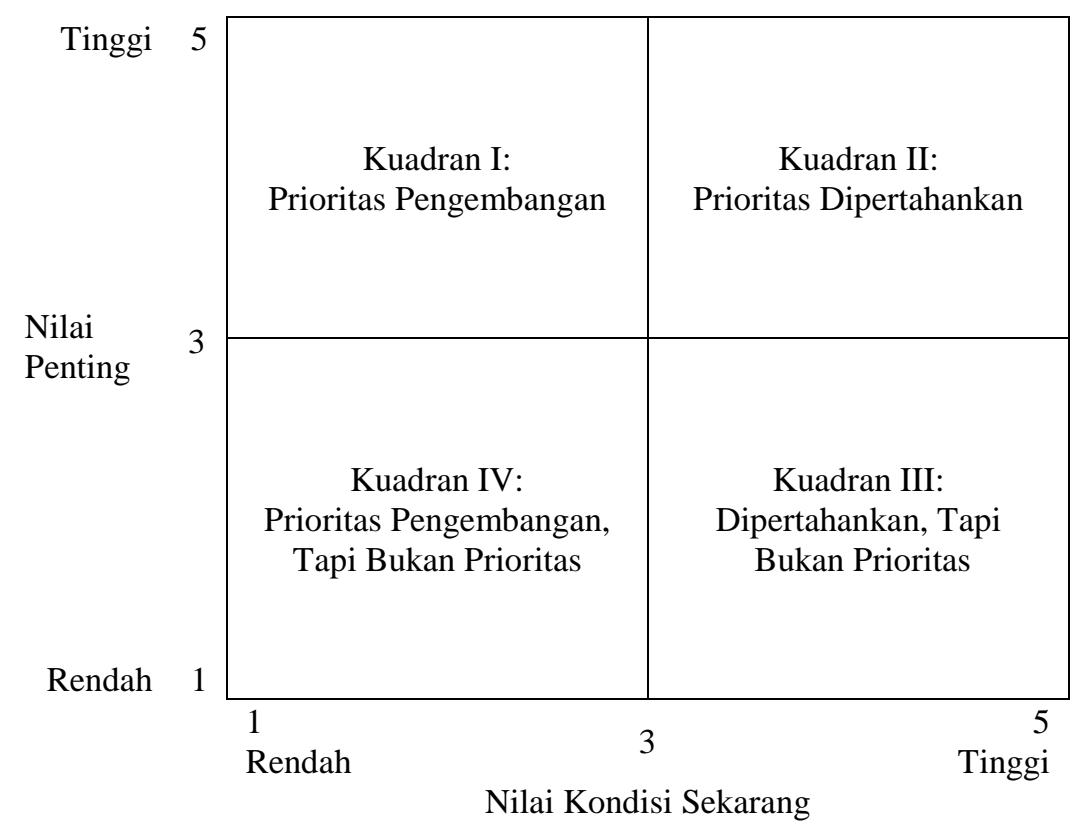

Gambar 1. Kuadran Nilai Penting dan Nilai Kondisi Sekarang

\section{ANALISIS DAN PEMBAHASAN}

\section{Analisis Penilaian Tingkat Keberlanjutan}

Berdasarkan penilaian tingkat keberlanjutan pada aspek teknis, didapatkan data nilai indeks tertinggi terdapat pada faktor ketersediaan suku cadang sebesar 80.00, sedangkan faktor cakupan pelayanan mendapatkan nilai terendah yaitu sebesar 66.67. Hasil rata-rata penilaian pada aspek teknis sebesar 67.81, sehingga termasuk dalam interval kategori cukup berkelanjutan. Hal ini sesuai dengan hasil obervasi yang menunjukkan bahwa prasarana SPAM berbasis masyarakat kota Blitar secara fisik belum mengalami kerusakan berat. Umur teknis prasarana SPAM belum melewati ambang batas yaitu selama 25 tahun [8].

Penilaian tingkat keberlanjutan pada aspek kelembagaan memperoleh hasil indeks tertinggi adalah faktor tanggap pengaduan pengguna sebesar 79.23. Sedangkan indeks terendah adalah faktor transparansi pengelolaan sebesar 43.33. Rendahnya transparansi pengelolaan dikarenakan kelompok pengelola belum menemukan mekanisme yang tepat untuk melaporkan kondisi keuangan kepada masyarakat pengguna. Adapun indeks rata-rata indeks keberlanjutan sebesar 64.44 dan termasuk dalam interval kategori cukup berkelanjutan.

Penilaian tingkat keberlanjutan pada aspek keuangan memperoleh hasil bahwa variabel biaya operasional pemeliharaan memiliki nilai indeks lebih rendah dibandingkan variabel iuran. Secara umum iuran yang ditetapkan terjangkau dan masyarakat pengguna rutin untuk melaksanakan pembayaran iuran. Namun demikian dana yang diterima dari iuran hanya cukup untuk membiayai pembelian listrik dan pemeliharaan ringan. Bila terjadi kerusakan berat, masyarakat akan mengumpulkan dana diluar iuran rutin.

Iuran penggunaan air yang harus dibayar oleh masyarakat dipergunakan untuk: membayar air minum, insentif kepada petugas pengelola prasarana sesuai kesepakatan, serta biaya operasi dan pemeliharaan prasarana. Besarnya harga air minum tersebut harus lebih murah dari harga air yang harus dibayar oleh masyarakat sebelum dilaksanakannya pengembangan sistem penyediaan air minum [1]. Hasil rata -rata indeks keberlanjutan ditinjau dari aspek keuangan adalah sebesar 66.21 dengan status tingkat keberlanjutan adalah cukup berkelanjutan.

Program penyediaan prasarana air minum berbasis masyarakat belum sepenuhnya mampu mengakomodasi keterlibatan masyarakat dalam kegiatannya. Informasi dari responden diperoleh fakta bahwa pendampingan masyarakat selama proses pembangunan hingga berakhirnya masa konstruksi belum berjalan secara optimal. Masyarakat hanya terlibat dalam pemilihan lokasi dan penentuan titik sambungan rumah, sedangkan pembangunan prasarana SPAM dilaksanakan oleh pihak lain tanpa melibatkan masyarakat.

Untuk mengatasi kendala tersebut, Pemerintah Kota Blitar perlu merencanakan anggaran yang membiayai tenaga ahli profesional dengan kualifikasi dan kompetensi dalam melakukan pendampingan masyarakat. Selain itu dalam menyelenggarakan penyediaan air minum dapat mengadopsi alur kegiatan program penyediaan air sejenis diluar DAK AM, seperti Program Penyediaan Air Minum dan Sanitasi Berbasis Masyarakat (PAMSIMAS) atau Second Water and Sanitation for Low Income Communities (WSLIC-2). Adapun tingkat keberlanjutan pengelolaan SPAM ditinjau dari aspek sosial sebesar 63.85 dengan status keberlanjutan cukup berkelanjutan.

Hasil penilaian keberlanjutan untuk aspek lingkungan diperoleh rata-rata penilaian sebesar 80.77 dengan status keberlanjutan sangat berkelanjutan. Namun demikian tetap diperlukan upaya perawatan dan perlindungan agar kondisi sumber air selalu terjaga, misalnya dengan konservasi vegetasi di sekitar sumber air.

Rekapitulasi kelima aspek menunjukkan bahwa aspek lingkungan merupakan aspek dengan nilai keberlanjutan tertinggi, dengan status keberlanjutan adalah sangat berkelanjutan. Sedangkan aspek dengan nilai indeks terendah adalah aspek sosial dengan status keberlanjutan adalah cukup berkelanjutan. Hasil penilaian tingkat keberlanjutan keseluruhan faktor dapat dilihat pada Tabel 5 berikut ini. 
Tabel 5. Penilaian Tingkat Keberlanjutan Pengelolaan SPAM

\begin{tabular}{|c|c|c|c|c|c|c|c|c|c|c|c|c|c|}
\hline \multirow{3}{*}{$\begin{array}{c}\text { Kode } \\
\text { I.1 }\end{array}$} & \multirow{3}{*}{$\begin{array}{l}\text { Faktor yang Dinilai } \\
\text { Kualitas Air Baku }\end{array}$} & \multirow{3}{*}{$\begin{array}{l}\mathbf{P} \\
1\end{array}$} & \multicolumn{5}{|c|}{ Rating } & \multirow{3}{*}{$\begin{array}{c}\mathbf{R} \\
18\end{array}$} & \multirow{3}{*}{$\begin{array}{c}\begin{array}{c}\text { Jumlah } \\
\text { Nilai }\end{array} \\
69\end{array}$} & \multirow{3}{*}{$\begin{array}{c}\text { Jumlah } \\
\text { Nilai Maks } \\
90\end{array}$} & \multirow{2}{*}{\multicolumn{2}{|c|}{ Indeks }} & \multirow{3}{*}{$\begin{array}{r}\text { NKS } \\
3,8\end{array}$} \\
\hline & & & \multirow{2}{*}{$\mathbf{1}$} & \multirow{2}{*}{2} & \multirow{2}{*}{$\begin{array}{l}3 \\
7\end{array}$} & \multirow{2}{*}{$\begin{array}{l}4 \\
7\end{array}$} & \multirow{2}{*}{$\begin{array}{l}5 \\
4\end{array}$} & & & & & & \\
\hline & & & & & & & & & & & 76,67 & 76,67 & \\
\hline I. 2 & Ketersediaan Air Baku & 2 & 0 & 0 & 2 & 15 & 1 & 18 & 71 & 90 & 78,89 & 78,89 & 3,9 \\
\hline I. 3 & Kinerja Pompa & 3 & 3 & 3 & 6 & 5 & 1 & 18 & 52 & 90 & 57,78 & 57,78 & 2,9 \\
\hline I. 4 & Ketersediaan Suku Cadang & 4 & 0 & 0 & 4 & 10 & 4 & 18 & 72 & 90 & 80,00 & 80,00 & 4,0 \\
\hline \multirow[t]{2}{*}{ I. 5} & Kinerja Reservoir & 5 & 9 & 4 & 0 & 3 & 2 & 18 & 39 & 90 & 43,33 & \multirow{2}{*}{58,33} & \multirow{2}{*}{2,9} \\
\hline & & 6 & 0 & 2 & 6 & 6 & 4 & 18 & 66 & 90 & 73,33 & & \\
\hline I.6 & Kinerja Pipa Distribusi & 7 & 1 & 5 & 3 & 5 & 4 & 18 & 60 & 90 & 66,67 & 66,67 & 3,3 \\
\hline I.7 & $\begin{array}{l}\text { Penambahan Sambungan } \\
\text { Rumah }\end{array}$ & 8 & 5 & 2 & 5 & 1 & 5 & 18 & 53 & 90 & 58,89 & 58,89 & 2,9 \\
\hline I.8 & Cakupan Pelayanan & 9 & 4 & 1 & 8 & 5 & 0 & 18 & 50 & 90 & 55,56 & 55,56 & 2,8 \\
\hline I.9 & Kualitas Air yang diterima & 10 & 0 & 3 & 14 & 50 & 11 & 78 & 303 & 390 & 77,69 & 77,69 & 3,9 \\
\hline \multirow[t]{2}{*}{ I.10 } & Kuantitas Air yang diterima & 11 & 6 & 0 & 25 & 42 & 5 & 78 & 274 & 390 & 70,26 & \multirow{2}{*}{69,49} & \multirow{2}{*}{3,5} \\
\hline & & 12 & 7 & 7 & 17 & 39 & 8 & 78 & 268 & 390 & 68,72 & & \\
\hline \multirow[t]{3}{*}{ I.11 } & $\begin{array}{l}\text { Kontinuitas Air yang } \\
\text { diterima }\end{array}$ & 13 & 12 & 2 & 0 & 53 & 11 & 78 & 283 & 390 & 72,56 & 70,77 & 3,5 \\
\hline & & 14 & 12 & 2 & 7 & 53 & 4 & 78 & 269 & 390 & 68,97 & & \\
\hline & & & & & & & & & & a-rata penilaian a & ek teknis & 67,81 & \\
\hline II. 1 & Keberadaan Pengelola & 15 & 12 & 4 & 9 & 11 & 42 & 78 & 301 & 390 & 77,18 & 77,18 & 3,9 \\
\hline II. 2 & Kinerja Pengelola & 16 & 9 & 5 & 6 & 51 & 7 & 78 & 276 & 390 & 70,77 & 7115 & 36 \\
\hline & & 17 & 12 & 1 & 1 & 58 & 6 & 78 & 279 & 390 & 71,54 & J & $J, 0$ \\
\hline II.3 & Transparansi Pengelolaan & 18 & 37 & 9 & 19 & 8 & 5 & 78 & 169 & 390 & 43,33 & 43,33 & 2,2 \\
\hline II.4 & Keberadaan Peraturan & 19 & 10 & 29 & 7 & 28 & 4 & 78 & 221 & 390 & 56,67 & 4833 & 24 \\
\hline & & 20 & 29 & 34 & 2 & 12 & 1 & 78 & 156 & 390 & 40,00 & & 2,4 \\
\hline II.5 & Kepuasan Pengguna & 21 & 4 & 11 & 19 & 40 & 4 & 78 & 263 & 390 & 67,44 & 67,44 & 3,4 \\
\hline II.6 & $\begin{array}{l}\text { Tanggap Pengaduan } \\
\text { Pengguna }\end{array}$ & 22 & 12 & 3 & 10 & 12 & 41 & 78 & 301 & 390 & 77,18 & 79,23 & 4,0 \\
\hline & & 23 & 12 & 2 & 4 & 11 & 49 & 78 & 317 & 390 & 81,28 & & \\
\hline & & & & & & & & & Rata-rata & enilaian aspek ke & mbagaan & 64,44 & \\
\hline III.1 & $\begin{array}{l}\text { Keberadaan Iuran } \\
\text { Masyarakat }\end{array}$ & 24 & 6 & 0 & 2 & 58 & 12 & 78 & 304 & 390 & 77,95 & 77,95 & 3,9 \\
\hline III.2 & Keterjangkauan Iuran & 25 & 0 & 4 & 46 & 28 & 0 & 78 & 258 & 390 & 66,15 & 66,15 & 3,3 \\
\hline III.3 & $\begin{array}{l}\text { Keteraturan Pembayaran } \\
\text { Iuran }\end{array}$ & 26 & 11 & 0 & 6 & 60 & 1 & 78 & 274 & 390 & 70,26 & 70,26 & 3,5 \\
\hline III.4 & $\begin{array}{l}\text { Kesesuaian Iuran dengan } \\
\text { BOP }\end{array}$ & 27 & 5 & 10 & 49 & 14 & 0 & 78 & 228 & 390 & 58,46 & 58,46 & 2,9 \\
\hline III. 5 & $\begin{array}{l}\text { Keberadaan Biaya } \\
\text { Pengembangan }\end{array}$ & 28 & 10 & 24 & 7 & 37 & 0 & 78 & 227 & 390 & 58,21 & 58,21 & 2,9 \\
\hline & & & & & & & & & Rata- & ta penilaian aspe & euangan & 66,21 & \\
\hline IV.1 & Partisipasi Masyarakat & 29 & 8 & 47 & 14 & 7 & 2 & 78 & 182 & 390 & 46,67 & 46,67 & 2,3 \\
\hline IV.2 & Pertemuan Masyarakat & 30 & 22 & 29 & 19 & 8 & 0 & 78 & 169 & 390 & 43,33 & 43,33 & 2,2 \\
\hline IV.3 & Kepedulian & 31 & 0 & 4 & 12 & 50 & 12 & 78 & 304 & 390 & 77,95 & 77,95 & 3,9 \\
\hline IV.4 & Keinginan Berkelanjutan & 32 & 1 & 6 & 14 & 40 & 17 & 78 & 300 & 390 & 76,92 & 76,92 & 3,8 \\
\hline IV.5 & Praktek penggunaan air & 33 & 11 & 1 & 12 & 29 & 25 & 78 & 290 & 390 & 74,36 & 74,36 & 3,7 \\
\hline & & & & & & & & & & a-rata penilaian & ek sosial & 63,85 & \\
\hline V.3 & Perlindungan Sumber Air & 34 & 1 & 9 & 4 & 27 & 37 & 78 & 324 & 390 & 83,08 & 80.77 & 4.0 \\
\hline & & 35 & 0 & 3 & 8 & 59 & 8 & 78 & 306 & 390 & 78,46 & & \\
\hline & & & & & & & & & Rata-ra & penilaian aspek & gkungan & 80,77 & \\
\hline
\end{tabular}




\section{Analisis Penilaian Faktor Penting}

Analisis Relative Importance Index (RII) dilakukan untuk mendapatkan tingkat kepentingan dan menyusun peringkat faktor-faktor yang mempengaruhi keberlanjutan pengelolaan SPAM berbasis masyarakat. Perhitungan RII dilakukan untuk setiap indikator dimana nilai RII berkisar antara 0 (minimum) hingga 1 (maksimum), semakin mendekati nilai 1 maka semakin berpengaruh faktor tersebut pada keberlanjutan pengelolaan SPAM. Nilai untuk masing-masing faktor diperoleh melalui penjumlahan nilai yang dipilih oleh responden.

Dari hasil perhitungan dan grafik nilai RII diketahui faktor-faktor yang mempengaruhi keberlanjutan pengelolaan SPAM berbasis masyarakat dengan nilai RII tertinggi adalah keberadaan iuran masyarakat (III.1). Untuk mendukung data dan memperkuat hasil yang diperoleh dari uji Relative Importance Index dilakukan Uji Confidence Interval. Dalam penentuan batas garis peringkat dilakukan dengan melihat dari nilai interval. Adapun untuk memberi peringkat pada Confidence Interval adalah sebagai berikut:
Batas Atas tertinggi $=5,061$

Batas Bawah terendah $=3,080$

Maka, interval kelas = BA tertinggi-BB terendah/ 4 $=5,061-3,080 / 4$

$$
=0,495
$$

Sehingga interval kelas untuk empat peringkat dapat dilihat pada Tabel 7 berikut:

Tabel 7. Peringkat Confidence Interval

\begin{tabular}{cccc}
\hline Peringkat & \multicolumn{3}{c}{ Interval } \\
\hline 4 & 3,080 & - & 3,575 \\
\hline 2 & 3,575 & - & 4,070 \\
\hline 3 & 4,070 & - & 4,566 \\
\hline 1 & 4,566 & - & 5,061 \\
\hline
\end{tabular}

Dari hasil uji relative importance index dan confidence interval maka didapat penilaian faktor penting sebagaimana terdapat pada Tabel 8 berikut.

Tabel 8. Relative Importance Index dan Confidence Interval

\begin{tabular}{|c|c|c|c|c|c|c|c|c|}
\hline Kode & Faktor Keberlanjutan & Jumlah & $\mathbf{N P}$ & RII & St Dev & BB & BA & CI \\
\hline I.1 & Kualitas Air Baku & 45 & 4,5 & 0,90 & 0,707 & 4,062 & 4,938 & 3 \\
\hline I. 2 & Ketersediaan Air Baku & 43 & 4,3 & 0,86 & 1,059 & 3,643 & 4,957 & 3 \\
\hline I. 3 & Kinerja Pompa & 46 & 4,6 & 0,92 & 0,516 & 4,280 & 4,920 & 2 \\
\hline I. 4 & Ketersediaan Suku Cadang & 40 & 4 & 0,80 & 0,471 & 3,708 & 4,292 & 3 \\
\hline I.5 & Kinerja Reservoir & 41 & 4,1 & 0,82 & 0,876 & 3,557 & 4,643 & 3 \\
\hline I.6 & Kinerja Pipa Distribusi & 41 & 4,1 & 0,82 & 0,876 & 3,557 & 4,643 & 3 \\
\hline I.7 & Penambahan Sambungan Rumah & 36 & 3,6 & 0,72 & 0,516 & 3,280 & 3,920 & 4 \\
\hline I.8 & Cakupan Pelayanan & 39 & 3,9 & 0,78 & 0,738 & 3,443 & 4,357 & 4 \\
\hline I.9 & Kualitas Air yang diterima & 43 & 4,3 & 0,86 & 0,949 & 3,712 & 4,888 & 3 \\
\hline I.10 & Kuantitas Air yang diterima & 43 & 4,3 & 0,86 & 0,823 & 3,790 & 4,810 & 3 \\
\hline I.11 & Kontinuitas Air yang diterima & 43 & 4,3 & 0,86 & 0,675 & 3,882 & 4,718 & 3 \\
\hline II.1 & Keberadaan Pengelola & 41 & 4,1 & 0,82 & 0,738 & 3,643 & 4,557 & 3 \\
\hline II. 2 & Kinerja Pengelola & 39 & 3,9 & 0,78 & 0,738 & 3,443 & 4,357 & 4 \\
\hline II. 3 & Transparansi Pengelolaan & 39 & 3,9 & 0,78 & 0,738 & 3,443 & 4,357 & 4 \\
\hline II. 4 & Keberadaan Peraturan & 34 & 3,4 & 0,68 & 0,516 & 3,080 & 3,720 & 4 \\
\hline II.5 & Kepuasan Pengguna & 39 & 3,9 & 0,78 & 0,876 & 3,357 & 4,443 & 4 \\
\hline II.6 & Tanggap Pengaduan Pengguna & 40 & 4 & 0,80 & 0,943 & 3,416 & 4,584 & 4 \\
\hline III.1 & Keberadaan Iuran Masyarakat & 48 & 4,8 & 0,96 & 0,422 & 4,539 & 5,061 & 1 \\
\hline III. 2 & Keterjangkauan Iuran & 40 & 4 & 0,80 & 1,054 & 3,347 & 4,653 & 4 \\
\hline III.3 & Kelancaran Pembayaran Iuran & 43 & 4,3 & 0,86 & 0,949 & 3,712 & 4,888 & 3 \\
\hline III.4 & Kesesuaian Iuran dengan BOP & 41 & 4,1 & 0,82 & 0,876 & 3,557 & 4,643 & 3 \\
\hline III. 5 & Keberadaan Biaya Pengembangan & 37 & 3,7 & 0,74 & 0,823 & 3,190 & 4,210 & 4 \\
\hline IV.1 & Partisipasi Masyarakat & 39 & 3,9 & 0,78 & 0,994 & 3,284 & 4,516 & 4 \\
\hline IV.2 & Pertemuan Masyarakat & 37 & 3,7 & 0,74 & 0,675 & 3,282 & 4,118 & 4 \\
\hline IV.3 & Kepedulian & 39 & 3,9 & 0,78 & 0,994 & 3,284 & 4,516 & 4 \\
\hline IV.4 & Keinginan untuk berkelanjutan & 40 & 4 & 0,80 & 0,667 & 3,587 & 4,413 & 3 \\
\hline IV.5 & Praktek penggunaan air & 39 & 3,9 & 0,78 & 0,738 & 3,443 & 4,357 & 4 \\
\hline V.1 & Perlindungan Air Baku & 41 & 4,1 & 0,82 & 0,738 & 3,643 & 4,557 & 3 \\
\hline
\end{tabular}


Langkah pertama dalam analisa prioritas pengembangan adalah menentukan key factors yang merupakan faktor-faktor yang dinilai penting dalam keberlanjutan pengelolaan SPAM. Data mengenai nilai keberlanjutan sekarang (NKS) diperoleh dari hasil ratarata penilaian tingkat keberlanjutan, sedangkan nilai penting (NP) merupakan hasil rata-rata penilaian faktor penting dalam keberlanjutan pengelolaan SPAM. Selanjutnya nilai penting dan nilai keberlanjutan sekarang dipergunakan untuk pemetaan key factors dan diklasifikasikan sesuai kuadran prioritas pengembangan. Hasil pemetaan ke dalam kuadran key factors dapat dilihat pada Gambar 2.
Berdasarkan kuadran key factors, dapat dilihat beberapa faktor keberlanjutan pengelolaan yang masuk kuadran satu yaitu kuadran prioritas pengembangan, antara lain: Kinerja Pompa, Kinerja Reservoar, Penambahan Sambungan Rumah, Cakupan Pelayanan, Transparansi Pengelolaan, Keberadaan Peraturan, Kesesuaian Iuran dengan BOP, Keberadaan Biaya Pengembangan, Partisipasi Masyarakat dan Pertemuan Masyarakat. Faktor - faktor tersebut tersebut merupakan faktor yang penting bagi keberlanjutan pengelolaan SPAM berbasis masyarakat namun kondisi keberlanjutan sekarang dinilai masih belum baik.

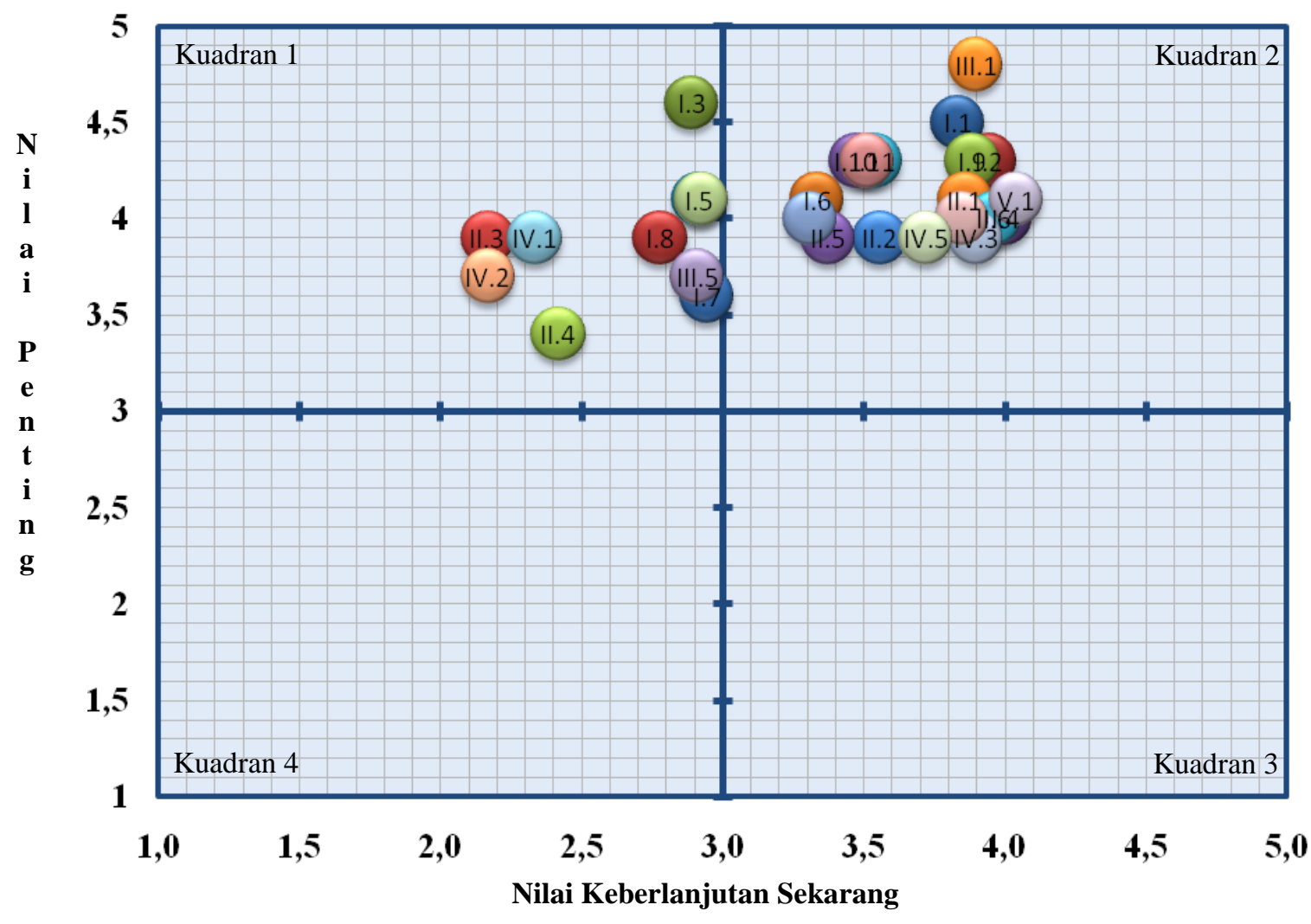

Gambar 2. Kuadran Key Factors

Dari hasil pemetaan key factors langkah berikutnya adalah menyusun indeks prioritas pengembangan (IPP), dimana semakin kecil nilai IPP per kuadran, maka faktor tersebut menjadi semakin diprioritaskan untuk dikembangkan. Urutan prioritas pengembangan berdasarkan IPP adalah Transparansi Pengelolaan, Pertemuan Masyarakat, Partisipasi Masyarakat, Kinerja Pompa, Kinerja Reservoir, Keberadaan Peraturan, Cakupan Pelayanan, Kesesuaian Iuran dengan BOP, Keberadaan Biaya Pengembangan dan Penambahan Sambungan Rumah.

Transparansi pengelolaan mempunyai arti bahwa seluruh kegiatan pengelolaan dapat diakses data/informasinya oleh masyarakat dan stakeholder. Kurangnya kapasitas dan kemampuan pengelola dalam membuat laporan keuangan merupakan penyebab utama. Diperlukan peran aktif Pemerintah dalam memfasilitasi pelatihan seperti teknis pengelolaan sistem penyediaan air minum, mekanisme pelaporan dan administrasi keuangan. Rendahnya transparansi pengelolaan yang dilakukan pihak pengelola dapat diatasi dengan melakukan mekanisme penerapan asas transparansi secara sederhana.
Kegiatan transparansi pengelolaan tersebut dapat diwujudkan sebagai berikut:

1. Menginformasikan penggunaan dana pengelolaan SPAM melalui pertemuan yang melibatkan masyarakat, semisal pertemuan tingkat Rukun Tetangga (RT),

2. Menampilkan laporan keuangan pada lokasi strategis,

3. Menyampaikan Laporan Pertanggung Jawaban (LPJ) ke pihak Kelurahan.

Pertemuan masyarakat merupakan media untuk menjembatani komunikasi antara pengelola dan pengguna SPAM. Saat pertemuan warga dapat digunakan untuk penyampaian kondisi pengelolaan SPAM kepada masyarakat (penerapan azas transparansi), penyampaian aspirasi masyarakat hingga pembayaran iuran air. Untuk meningkatkan partisipasi masyarakat diperlukan kerjasama antar stakeholder yang terlibat dalam pengelolaan SPAM.

Partisipasi masyarakat dapat ditingkatkan dengan melibatkan masyarakat dalam pemilihan pengurus SPAM secara demokratis hingga mengadakan kegiatan gotong royong dalam rangka melakukan perawatan dan 
pemeliharaan prasarana SPAM. Pemerintah dalam memberdayakan masyarakat dapat menggunakan jasa fasilitator air bersih atau lembaga swadaya masyarakat yang bergerak di bidang pendampingan masyarakat. Adanya fasilitator dalam kegiatan pendampingan masyarakat dapat mengedukasi masyarakat untuk berperan aktif dalam menjaga keberlanjutan pengelolaan SPAM pada masing-masing wilayah.

Kinerja pompa dan reservoir merupakan faktor teknis yang memerlukan pengembangan. Kondisi pompa yang hanya berjumlah satu unit pada masing-masing lokasi memerlukan perawatan secara rutin agar kinerja pompa tetap optimal. Selain itu hal yang dapat dilakukan dalam menjaga kinerja pompa adalah dengan mengatur jadwal operasional pompa dan menyediakan pompa cadangan agar sistem dapat bekerja secara bergantian.

Adanya peraturan dalam pengelolaan bertujuan agar proses pengelolaan dan pelayanan SPAM dapat beroperasi dan terkoordinasi dengan baik, sehingga
SPAM yang terbangun dapat memenuhi kebutuhan masyarakat pengguna baik secara kualitas, kuantitas dan kontinyuitas. Peraturan dalam pengelolaan dapat mengacu pada peraturan perundangan tentang SPAM, salah satunya adalah Permen PUPR 26/2014 tentang Prosedur Operasional Standar Pengelolaan Sistem Penyediaan Air Minum [9].

Pemerintah Kota Blitar dalam mengembangkan keberlanjutan SPAM dapat menyusun regulasi, menginisiasi forum antar kelompok masyarakat pengelola di tingkat kota, hingga pemberian penghargaan dan sanksi untuk menstimulasi kinerja pengelola SPAM. Misalnya dengan pemberian bantuan hibah bagi unit SPAM yang memiliki tingkat keberlanjutan baik berupa bantuan operasional atau penambahan kapasitas jaringan distribusi dan sambungan rumah. Adapun hasil perhitungan indeks prioritas pengembangan secara keseluruhan terdapat pada Tabel 9 berikut.

Tabel 9. Indeks Prioritas Pengembangan

\begin{tabular}{|c|c|c|c|c|c|c|}
\hline \multicolumn{2}{|c|}{ Kode } & Faktor & NP & NKS & NKSS & IPP \\
\hline & II.3 & Transparansi Pengelolaan & 3,9 & 2,2 & $-2,31$ & $-9,00$ \\
\hline & IV.1 & Pertemuan Masyarakat & 3,7 & 2,2 & $-2,31$ & $-8,54$ \\
\hline $\begin{array}{l}\mathbf{n} \\
\mathrm{U}\end{array}$ & IV.2 & Partisipasi Masyarakat & 3,9 & 2,3 & $-2,14$ & $-8,36$ \\
\hline \multirow{4}{*}{$\begin{array}{l}\mathrm{A} \\
\mathrm{D} \\
\mathrm{R} \\
\mathrm{A} \\
\mathrm{N}\end{array}$} & I.1 & Kinerja Pompa & 4,6 & 2,9 & $-1,73$ & $-7,96$ \\
\hline & $\mathrm{I} .3$ & Kinerja Reservoir & 4,1 & 2,9 & $-1,71$ & $-7,03$ \\
\hline & II.4 & Keberadaan Peraturan & 3,4 & 2,4 & $-2,07$ & $-7,03$ \\
\hline & I.6 & Cakupan Pelayanan & 3,9 & 2,8 & $-1,80$ & $-7,02$ \\
\hline \multirow{3}{*}{1} & III.4 & Kesesuaian Iuran dengan BOP & 4,1 & 2,9 & $-1,71$ & $-7,01$ \\
\hline & III.5 & Keberadaan Biaya Pengembangan & 3,7 & 2,9 & $-1,72$ & $-6,36$ \\
\hline & I.5 & Penambahan Sambungan Rumah & 3,6 & 2,9 & $-1,70$ & $-6,11$ \\
\hline \multirow{10}{*}{$\begin{array}{l}\mathrm{K} \\
\mathrm{U} \\
\mathrm{A} \\
\mathrm{D} \\
\mathrm{R} \\
\mathrm{A} \\
\mathrm{N}\end{array}$} & I.8 & Kuantitas Air yang diterima & 4,3 & 3,5 & $-1,44$ & $-6,19$ \\
\hline & III.1 & Keberadaan Iuran Masyarakat & 4,8 & 3,9 & $-1,28$ & $-6,16$ \\
\hline & III.3 & Kelancaran Pembayaran Iuran & 4,3 & 3,5 & $-1,42$ & $-6,12$ \\
\hline & I.9 & Kontinuitas Air yang diterima & 4,3 & 3,5 & $-1,41$ & $-6,08$ \\
\hline & III. 2 & Keterjangkauan Iuran & 4 & 3,3 & $-1,51$ & $-6,05$ \\
\hline & II.5 & Kepusan Pengguna & 3,9 & 3,4 & $-1,48$ & $-5,78$ \\
\hline & I.7 & Kualitas Air yang diterima & 4,3 & 3,9 & $-1,29$ & $-5,53$ \\
\hline & V.1 & Kualitas Air Baku & 4,5 & 4,0 & $-1,24$ & $-5,59$ \\
\hline & II.2 & Kinerja Pengelola & 3,9 & 3,5 & $-1,41$ & $-5,50$ \\
\hline & II.1 & Keberadaan Pengelola & 4,1 & 3,9 & $-1,30$ & $-5,31$ \\
\hline \multirow[t]{8}{*}{2} & IV.5 & Praktek Pengguna Air & 3,9 & 3,7 & $-1,34$ & $-5,24$ \\
\hline & IV.4 & Keinginan untuk berkelanjutan & 4 & 3,8 & $-1,30$ & $-5,20$ \\
\hline & II.6 & Tanggap Pengaduan Pengguna & 4 & 3,9 & $-1,27$ & $-5,08$ \\
\hline & V.3 & Perlindungan Air Baku & 4,1 & 4,0 & $-1,24$ & $-5,08$ \\
\hline & IV.3 & Kepedulian & 3,9 & 3,9 & $-1,28$ & $-5,00$ \\
\hline & I.4 & Kinerja Pipa Distribusi & 4,1 & 4,1 & $-1,21$ & $-4,95$ \\
\hline & I. 2 & Ketersediaan Suku Cadang & 4 & 4,0 & $-1,24$ & $-4,95$ \\
\hline & V.2 & Ketersediaan Air Baku & 4,3 & 4,4 & $-1,15$ & $-4,93$ \\
\hline
\end{tabular}




\section{KESIMPULAN}

Berdasarkan hasil penilaian keberlanjutan pengelolaan sistem penyediaan air minum yang telah dilakukan. Diambil beberapa kesimpulan sebagai berikut:

1. Penilaian keberlanjutan pengelolaan SPAM berbasis masyarakat di Kota Blitar ditinjau dari aspek teknis, kelembagaan, keuangan, dan sosial menunjukkan hasilberkelanjutan sedangkan aspek lingkungan mendapatkan hasil sangat berkelanjutan.

2. Hasil analisa dengan metode Relative Importance Index menunjukkan faktor Keberadaan Iuran Masyarakat sebagai faktor paling penting dalam keberlanjutan pengelolaan SPAM.

3. Berdasarkan analisa Indeks Prioritas Pengembangan dapat diketahui faktor-faktor yang memerlukan pengembangan dalam pengelolaan SPAM, dengan prioritas penanganan yang perlu dilakukan yaitu: peningkatkan transparansi pengelolaan, pertemuan dan partisipasi masyarakat, optimalisasi kinerja pompa dan reservoir, menyusun peraturan pengelolaan, meningkatkan cakupan pelayanan dengan menambah sambungan rumah, serta menetapkan iuran yang sesuai dengan kebutuhan operasional pemeliharaan.

Ketidaksesuaian dana yang diterima dari iuran untuk operasional pemeliharaan merupakan permasalahan krusial dalam keberlanjutan pengelolaan SPAM. Besarnya iuran harus mempertimbangkan kebutuhan biaya operasional dan pemeliharaan penyelenggaraan SPAM. Perhitungan dan penetapan besaran iuran di dasarkan pada prinsip: keterjangkauan dan keadilan, mutu pelayanan, pemulihan biaya, efisiensi pemakaian air, transparansi dan akuntabilitas dan perlindungan dan pelestarian air baku. Untuk itu diperlukan adanya penelitian lanjutan terhadap kajian penetapan iuran sesuai kemampuan masyarakat yang dapat mendukung biaya operasional dan pemeliharaan.

\section{DAFTAR PUSTAKA}

[1] Permen PUPR 33/2016, Penyelenggaraan Dana Alokasi KhususBidang Infrastruktur, Jakarta.

[2] Schuringa, W. (1998), Community Management Models for Small Scale Water Supply Systems, IRC International Water and Sanitation Center, Kenya.

[3] Jones, S.A., Anya, A.,Stacey,N., and Weir, L. (2012), A Life-cycle Approach to Improve the Sustainability of Rural Water Systems in ResourceLimited Countries, Journal, Challenges 2012,3,233260.

[4] Aslam, M.S. (2013), Sustainability of CommunityBased Drinking Water Systems in Developing Countries, Thesis, McGill University, Montreal, Quebec, Canada.

[5] Sugiyono. (2012), Metode Penelitian Kuantitatif Kualitatif dan R\&D. Bandung : Alfabeta
[6] Shobari, I (2015), Faktor-faktor yang Mempengaruhi Rendahnya Kualitas Desain Konstruksi di Perguruan Tinggi Negeri di Surabaya, Prosiding Seminar Nasional Manajemen Teknologi XXIII, Program Studi MMT-ITS, Surabaya 1 Agustus 2015.

[7] Wijayanto, D. (2015), Analisi Inventarisasi Masalah dan Pengembangan Solusi dalam Pengembangan Perikanan Artisanal di Pantai Kedongan Bali, Jurnal Saintek Perikanan Vol. 11 No.1: 17-25, Agustus 2015.

[8] Permen PUPR 18/2007, Penyelenggaraan Sistem Penyediaan Air Minum, Jakarta.

[9] Permen PUPR 26/2014, Prosedur Operasional Standar Pengelolaan Sistem Penyediaan Air Minum, Jakarta. 